\title{
Culture Shock and the Overseas Trainee*
}

\author{
By John L. Cox
}

The term Culture Shock describes the complex gamut of feelings experienced following an abrupt change of environment, as when an individual moves country. This event causes a discontinuity of social relationships previously relied on for the maintenance of self-esteem and frequently taken entirely for granted.

Fifty per cent of trainee psychiatrists in Britain have had their undergraduate training overseas (Brook, 1975; Cox, 1979); many must have migrated across continents, and such trainees may well experience a culture shock when first working in Britain. In some circumstances this may interfere markedly with initial job satisfaction and subsequent training progress; being uprooted can be both unpleasant and also associated with a nostalgia for the comforts of old friends, familiar food or consistent customs (Zwingmann, 1973). This nostalgic reaction may also include anxiety, irritability and depression, and may have some similarities with a bereavement response which follows a 'loss' life event.

For some trainees an insight into these emotional changes during acculturation may be of crucial importance for their work satisfaction. It may also be an advantage if their tutors can share these insights and are themselves familiar with the difficulties. Anumonye (1967) has clearly categorized these problems for African students, as being either inevitable or avoidable. An understanding of the time scale of acculturation adjustments may also be an advantage. Gullahorn \& Gullahorn (1963) have likened the phases of acculturation to the shape of a U-curve, in which feelings of well-being are eventually re-experienced after a period of dissatisfaction with the new surroundings. This U-curve can, for some students, appropriately be extended to a ' $W$ ' curve, to take into account reverse culture shock on return to the home environment.

In a recent study of overseas undergraduates at Edinburgh (Miller et al. 1980) the most conspicuous psychiatric problems were found to occur during the Easter term of the first year, when dissatisfaction may be maximal, and it seems probable that the same process may occur for overseas postgraduate students. Practical experience in supervising overseas postgraduate trainees suggests that their performance is rarely optimal until the second year. Only then has the 'effective function phase' of culture shock been reached and the disenchantment period, with its threat of examination failure, feelings of alienation or desire to return home, been successfully negotiated (Brink \& Saunders, 1976).
Not all overseas trainees will experience such difficulties, and for some, acculturation is gradual and painless; the individual thrives in the new environment and 'never looks back'. It is nevertheless likely that for the trainee who has moved continents, culture shock may be a vivid experience; the climate, clothes, food, language and family obligations of British society may contrast markedly with the home environment. Furthermore, because many such trainees work in isolated psychiatric hospitals, there may be a temptation for the trainee to retreat yet further to the books or to take refuge in his own ethnic group. If this happens, the local socio-cultural customs may be regarded as irrelevant, or totally impossible to grasp to any useful extent, and the acculturation difficulties are then exacerbated.

It is hoped that a more thorough understanding of these interrelationships between acculturation and training by both trainees and tutors will alleviate some personal distress and so increase the quality of psychiatric service provided. Such knowledge may also encourage the development of a sustained postgraduate training programme for all trainees, regardless of the place of work or the intonation of the mother tongue.

-This note will appear in the next edition of the Handbook for Inceptors and Trainees in Psychiatry

\section{REFERENCES}

ANUmonye, A. (1967) Psychological stresses among African students in Britain. Scottish Medical Journal, 12, 314.

Brink, P. J. \& SAUnders, J. M. (1976) Transcultural Nursing. A Book of Readings (edited P. J. Brink) p 126. New Jersey: Prentice Hall Inc.

Brook, P. (1975) Training opportunities for overseas psychiatrists. British Journal of Psychiatry, 127, 179-84.

Cox, J. L. (1979) Overseas psychiatrists in Scotland. Bulletin of the Royal College of Psychiatrists. April 1979, p 72.

GULlahorn, J. T. \& GuLlahorN, J. E. (1963) An extention of the U-curve hypothesis. Journal of Social Issues, 19; p 33-47.

Miller, P. McC., BABIKER, I. E. and Cox, J. L. (1980) Background, life circumstances, symptoms and academic performance in overseas students. Submitted for publication.

Zwingmann, C. (1973) The nostalgic phenomenon and its exploitation. In Uprooting and After (Ed. C. Zwingmann \& $M$. PfisterAmende). New York: Springer Verlag. 